\title{
Abstract
}

\section{Descriptive Epidemiology of Acute Flaccid Paralysis Cases in Afghanistan, 2015-2018}

\author{
Homeira Nishat $^{1 *}$, BSc, MD; Khwaja Mir Islam Saeed ${ }^{2 *}$, DVMS, MD, MSc \\ ${ }^{1}$ Research Department, Afghanistan National Public Health Institute, Kabul, Afghanistan \\ ${ }^{2}$ Training Department, Afghanistan National Public Health Institute, Kabul, Afghanistan \\ *all authors contributed equally
}

\section{Corresponding Author:}

Homeira Nishat, BSc, MD

Research Department

Afghanistan National Public Health Institute

Cinema Oamir, Blood Bank

Kabul, 0093

Afghanistan

Phone: 93787042813

Email: homeiragulzar@gmail.com

\section{Abstract}

Background: Polio is on the verge of eradication, while Afghanistan and Pakistan are the only endemic countries remaining where polio is still prevalent. Surveillance for acute flaccid paralysis (AFP) is one of the four cornerstone strategies of the Polio Eradication Initiative.

Objective: This study aims to describe the epidemiology of AFP cases in terms of time, place, and person.

Methods: It is a descriptive study whereby we analyzed the secondary data reported by AFP surveillance in Afghanistan. We accessed and used line lists from 2015 to 2018 to describe the epidemiological status of AFP cases in the country. With the use of Epi Info 7 and Microsoft Excel, we calculated descriptive measures, including frequencies, mean, median, SD, generated proportions, tables, and graphs.

Results: Overall, 11,513 cases were reported in the last 4 years (2015-2018) by AFP surveillance at the Ministry of Public Health. The majority of the cases (29\%) were reported in 2018, while 2088 (18\%) cases were reported in 2015 . The trend of oral polio vaccination has increased from 2015 to 2018 (57\%, 64\%, 63\%, and 68\%, respectively). Most of the cases were reported from southern and western regions, and $57 \%$ were male cases. The highest (38\%) proportions of cases were in those less than 30 months in age. Guillain-Barre syndrome was $38 \%$ of all categories. The samples were collected using appropriate procedures. However, the numbers of confirmed cases increased from 13 in 2016 to 14 in 2017, 20 in 2018, and 22 in 2019.

Conclusions: The AFP surveillance system is well established in the country. Nevertheless, with the increase in the trend of oral polio vaccine coverage, there is also an increase in the number of confirmed polio cases. Hence, the system should be sustained, and strategies should be strengthened to focus on the southern region as being the main engine of polio in the country.

(iproc 2022;8(1):e36530) doi: $10.2196 / 36530$

\section{KEYWORDS}

epidemiology; acute flaccid paralysis; poliomyelitis; Afghanistan

\section{Abbreviations \\ AFP: acute flaccid paralysis}


Edited by Y Khader; this is a non-peer-reviewed article. Submitted 17.01.22; accepted 18.01.22; published 04.02.22.

Please cite as:

Nishat H, Saeed KMI

Descriptive Epidemiology of Acute Flaccid Paralysis Cases in Afghanistan, 2015-2018

iproc 2022;8(1):e36530

URL: https://www.iproc.org/2022/1/e36530

doi: $\underline{10.2196 / 36530}$

PMID:

(CHomeira Nishat, Khwaja Mir Islam Saeed. Originally published in Iproceedings (https://www.iproc.org), 04.02.2022. This is an open-access article distributed under the terms of the Creative Commons Attribution License (https://creativecommons.org/licenses/by/4.0/), which permits unrestricted use, distribution, and reproduction in any medium, provided the original work, first published in Iproceedings, is properly cited. The complete bibliographic information, a link to the original publication on https://www.iproc.org/, as well as this copyright and license information must be included. 